\title{
ESCOLA E DESENVOLVIMENTO DA SUBJETIVIDADE: UM DIÁLOGO ENTRE TEORIAS
}

\author{
Renato Kendy Hidaka
}

Universidade Estadual Paulista - UNESP, Programa de Pós-graduação em Ciências Sociais, Marília, SP. E-mail: rkhidaka@ifsp.edu.br.

\section{RESUMO}

Atualmente, uma parte das pesquisas brasileiras realizadas no campo da educação têm procurado articular as contribuições da pedagogia histórico-crítica, formulada por D. Saviani, às contribuições da teoria histórico-cultural, originada com os estudos de L. Vigotski no campo da psicologia. Tais pesquisas têm sustentado a existência de um caminho profícuo aberto pela relação estabelecida entre essas duas teorias, como, por exemplo, o desenvolvimento da reflexão sobre o papel da escola no desenvolvimento da subjetividade humana. Este artigo tem como objetivo fazer alguns apontamentos sobre a relação entre escola e desenvolvimento da subjetividade a partir do diálogo entre as contribuições da teoria histórico-cultural e da pedagogia histórico-crítica e formulações constantes na obra A construção social da realidade, dos sociólogos P. Berger e T. Luckmann. Sustenta-se que essa articulação, ao atentar para a dimensão institucional da formação da subjetividade humana, contribui para uma reflexão mais abrangente sobre o tema em questão.

Palavras-chave: escola, subjetividade, educação, indivíduo, sociedade.

\section{SCHOOL AND SUBJECTIVITY DEVELOPMENT: A DIALOGUE BETWEEN THEORIES}

\begin{abstract}
Currently, a part of brazilian's researchs in the field of education has sought to articulate the contributions of historical-critical pedagogy, formulated by D. Saviani, to the contributions of historical-cultural theory, originated with L. Vigotski's studies in the field of psychology. Such researchs has supported the existence of a fruitful path opened by the relationship established between these two theories, such as the development of reflection on the role of school in the development of human subjectivity. This article aims to make some considerations about the relationship between school and the development of subjectivity from the dialogue between the contributions of historical-cultural theory and historical-critical pedagogy and constant formulations in the work The social construction of reality, by sociologists $\mathrm{P}$. Berger and $\mathrm{T}$. Luckmann. It is argued that this articulation, while attentive to the institutional dimension of the formation of human subjectivity, contributes to a more comprehensive reflection on the subject in question.
\end{abstract}

Keywords: School, subjectivity, education, individual, society. 


\section{INTRODUÇÃO}

A produção científica acadêmica a respeito da relação entre escola e subjetividade adquiriu novo sentido e significado no Brasil com a incorporação das contribuições da teoria históricocultural ao campo da educação. No atual estágio de desenvolvimento teórico das pesquisas realizadas no interior desse campo científico, os esforços de intelectuais brasileiros têm se voltado à articulação entre teoria histórico-cultural e pedagogia histórico-crítica. Neste texto, procuro estabelecer um diálogo entre tais contribuições - utilizadas como fundamento teórico da reflexão a ser empreendida - e algumas proposições extraídas da obra A construção social da realidade: tratado de sociologia do conhecimento, dos sociólogos de Peter L. Berger e Thomas Luckmann. Procuro sustentar que nessa obra encontram-se formulações que são úteis para a compreensão do papel das instituições sociais no processo de socialização e, por conseguinte, na formação da subjetividade. Diante disso, destaco o papel da escola, tal como compreendida pela pedagogia histórico-crítica, no desenvolvimento individual da subjetividade social humana.

\section{METODOLOGIA}

Este trabalho se configura como um ensaio teórico, sendo o resultado de uma pesquisa de abordagem qualitativa. O procedimento adotado aqui foi a pesquisa bibliográfica voltada à análise e interpretação de textos de referência sobre o tema investigado (GERHARDT; SILVEIRA, 2009). Parto da exposição da discussão de Berger e Luckmann (1985) sobre a determinação sociocultural da individualidade humana e do papel que as instituições sociais exercem no processo de socialização para, em seguida, relacioná-la com a discussão acerca do papel da atividade (LEONTIEV, 2004) e da escola na formação da subjetividade (DUARTE, 2013; MARTINS, 2011; SAVIANI, 1996, 2003).

\section{RESULTADOS}

Destaco, como resultados principais, o diálogo possível entre pedagogia histórico-crítica, psicologia histórico-cultural e algumas formulações sociológicas contidas na obra $A$ construção social da realidade. Sustento que as contribuições de Berger e Luckmann (1985) são complementares às formulações da pedagogia histórico-crítica e da teoria histórico-cultural acerca da formação da subjetividade humana no processo de ensino-aprendizagem escolar.

\section{DISCUSSÃO}

Em A construção social da realidade, o processo de formação da individualidade é examinado por Berger e Luckmann na sua dimensão ontogenética. De acordo com os autores (1985, p.70), "todos os animais não humanos, enquanto espécies e enquanto indivíduos, vivem em mundos fechados, cujas estruturas são predeterminadas pelo equipamento biológico das diversas espécies". Diferentemente das outras espécies de animais, a relação do Homo sapiens com a realidade exterior é de abertura: "o organismo humano é capaz de aplicar o equipamento que possui por constituição a uma ampla escala de atividades e, além disso, constantemente variável e em variação".

Embora ontogeneticamente necessário, o dispositivo biológico do qual os homens são portadores é, por si só, segundo Berger e Luckmann, insuficiente para promover o desenvolvimento orgânico da vida humana. Este, com efeito, é dependente da interferência das determinações socioculturais. Nesse sentido, afirmam que: "Não apenas a sobrevivência da criança humana depende de certos dispositivos sociais, mas a direção de seu desenvolvimento é socialmente determinada." (1985, p.71).

Sobre a formação da subjetividade, que é o que nos interessa aqui, Berger e Luckmann assinalam que: 
O período durante o qual o organismo humano se desenvolve até completar-se na correlação com o ambiente é também o período durante o qual o eu humano se forma. Por conseguinte, a formação do eu deve também ser compreendida em relação com o contínuo desenvolvimento orgânico e com o processo social, no qual o ambiente natural e o ambiente humano são mediatizados pelos outros processos significativos. [...] Os mesmos processos sociais que determinam a constituição do organismo produzem o eu em sua forma particular, culturalmente relativa. $(1985, \mathrm{p}$. 73).

A constituição do "eu", ou o que podemos chamar de individualidade, ocorre assim com base em um processo de apropriação subjetiva do mundo social pelo indivíduo singular. Sendo o mundo social uma realidade objetiva dotada de significados construídos socialmente, os homens precisam assimilar subjetivamente esses significados para atuar em sociedade. Ao fazê-lo, transformam o mundo social em uma realidade subjetiva dotada de sentidos para eles. Na dialética da sociedade, os homens, por meio das atividades sociais que realizam, exteriorizam o seu próprio ser no mundo; essa exteriorização, todavia, tem como condição a interiorização anterior deste mesmo mundo como realidade subjetiva. É nessa perspectiva que os homens não nascem, mas tornam-se membros da sociedade ao interiorizarem-exteriorizarem-objetivarem atividades sociais determinadas.

A compreensão do significado dos conceitos de interiorização, exteriorização e objetivação é importante para a compreensão das formulações de Berger e Luckmann. Ater-me-ei brevemente a eles. Começo pelos conceitos de exteriorização e objetivação, úteis para a análise da dimensão objetiva da sociedade. Ao referirem-se à dimensão objetiva da sociedade, Berger e Luckmann têm em vista a exteriorização e a objetivação das atividades humanas. Essas atividades, quando tipificadas, dão forma à determinadas instituições sociais. Um exemplo concreto: a tipificação da prática pedagógica escolar corresponde a formação da instituição escolar. Esta é caracterizada por atividades que exteriorizam e objetivam práticas específicas, no caso, a prática de ensino, realizada pelo agente-professor, que visa a transmissão de conhecimentos escolares, campo em que dominam as atividades didáticas docentes, e a prática de aprendizagem, em que se desenvolvem atividades, por parte dos agentes-alunos, que visam a assimilação de conhecimentos pertinentes ao arbitrário cultural escolar.

O conceito de interiorização tem relação direta com a dimensão subjetiva da sociedade. A interiorização é momento inicial do processo de relacionamento dos indivíduos com o mundo exterior, que compreende a apreensão dos significados e a atribuição de sentido aos elementos componentes da realidade objetiva. Berger e Luckmann (1985) empregam o termo socialização para conceituar o processo de interiorização no qual ocorre a introdução do indivíduo nas diversas esferas sociais correspondentes à realidade objetiva. A socialização é um processo que se inicia com o nascimento do indivíduo e somente finda com a sua morte. Nesse processo, o indivíduo se apropria de valores, conhecimentos, normas, modos de agir e pensar característicos de uma sociedade. Ele é dividido pelos autores em dois momentos: a socialização primária e a socialização secundária.

A socialização primária corresponde ao saber básico que é assimilado pelo indivíduo para estruturar a sua relação com o mundo objetivo. Ocorre na fase da infância e, em quase todas as sociedades existentes, realiza-se no seio da instituição familiar. A socialização secundária consiste em "qualquer processo subsequente que introduz um indivíduo já socializado em novos setores do mundo objetivo de sua sociedade" (1985, p. 175). Exemplos de instituições que realizam a socialização secundária: a escola, que ensina aos indivíduos o saber científico escolar e valores da cidadania; a igreja, responsável por transmitir comportamentos e valores religiosos de 
determinado tipo; a universidade, que ensina valores e comportamentos pertinentes à determinada ocupação sócio profissional, etc.

Para Berger e Luckmann (1985), a socialização, primária e secundária, deve ser pensada como um processo relacional, no qual o indivíduo, em contato com outros indivíduos e no interior de uma instituição social, interioriza e exterioriza valores e comportamentos sociais tipificados. Eis aqui o ponto de conexão entre mundo objetivo e subjetivo. Complementando a exposição feita acima, pode-se dizer que as instituições sociais são entendidas assim, por Berger e Luckmann, como conjunto complexo organizado de atividades sociais tipificadas realizadas por agentes sociais específicos que assumem determinados papéis sociais. A escola, para empregar a definição acima, pode ser entendida enquanto uma instituição social constituída por agentes que encarnam papéis sociais específicos (professores, alunos, diretores, coordenares pedagógicos, etc.) na qual se realizam atividades sociais específicas (de interiorização-exteriorização-objetivação) correspondentes (por exemplo, atividades de ensino, atividades de estudo-aprendizado, atividade de gestão, etc.).

O limite da abordagem sociológica de Berger e Luckmann está situado na circunscrição da análise do desenvolvimento da subjetividade à dimensão social. De outro modo, estou a dizer que tais autores nada dizem sobre o processo de aprendizagem e de desenvolvimento individual dos homens. Isso significa que, malgrado nos auxiliem na compreensão dos elementos sociais constituintes da subjetividade, a abordagem de Berger e Luckmann não nos dá resposta à questão: como os indivíduos aprendem e se desenvolvem intelectualmente? Neste ponto é que as contribuições da teoria histórico cultural e da pedagogia histórico-crítica para a compreensão desse processo são de grande relevância.

Ao investigar a relação entre desenvolvimento humano e aprendizagem, L. Vigotski, partindo do campo da psicologia russa, produziu um conjunto de proposições teóricas que nos auxiliam na compreensão do desenvolvimento do psiquismo, bem como na compreensão de sua relação com a formação da subjetividade. Como se sabe, diferentemente de J. Piaget, que norteou suas pesquisas sobre o desenvolvimento do pensamento da criança isolando analiticamente o desenvolvimento intelectual do processo de aprendizagem, as investigações de Vigotski têm como premissa o fator decisivo exercido pela aprendizagem no processo de desenvolvimento humano. Para Vigotski (1988), a estrutura dos processos intelectuais do homem é impulsionada pela aprendizagem, ou seja, pela apropriação que o indivíduo faz de estímulos exteriores. Nesse processo, elementos da realidade externa são transformados, em vista das capacidades biológicas humanas, em processos psíquicos funcionais internos, as chamadas funções psíquicas superiores. Entre essas funções, estão: o desenvolvimento da linguagem oral e escrita, da memória, do cálculo, do pensamento e do controle da conduta. Pode-se afirmar, por conseguinte, que essas funções (a memória, o cálculo, a linguagem oral e escrita, etc.) antes de serem internalizadas, devem ser vivenciadas/experienciadas (atividade intrapsíquica) individualmente para assim se tornarem capacidades humanas. É um processo que vai da experiência externa à apropriação interna. (MELLO, 2004).

Essa relação entre realidade exterior e desenvolvimento interno do psiquismo é, na perspectiva da teoria histórico-cultural, mediada pela atividade social. A realização da atividade em determinadas formas histórico-sociais impõe aos indivíduos um processo de subjetivação dessas formas e, de modo imanente a esse processo, implica em transformações em sua constituição psíquica, com o desenvolvimento de funções cognitivas cada vez mais complexas (LEONTIEV, 2004).

Ao aliar as contribuições da psicologia soviética histórico-cultural à pedagogia históricocrítica, pesquisadores brasileiros avançaram nos estudos sobre a formação da individualidade e sobre o papel exercido pela educação escolar nesse processo. Os trabalhos desses pesquisadores têm incorporado a perspectiva da pedagogia histórico-crítica, segundo a qual o trabalho educativo 
desempenha um papel fundamental no desenvolvimento da individualidade/subjetividade humana. É o trabalho educativo, enquanto ato intencional, que produz em cada indivíduo singular a humanidade que vem sendo produzida historicamente (SAVIANI, 2003). Nessa perspectiva, o trabalho educativo contribui para o desenvolvimento da individualidade no processo de transmissão, por parte do educador, e assimilação, por parte do educando, do conjunto de valores, conhecimentos, normas, regras de um determinado estágio de desenvolvimento da cultura.

Para que esse trabalho educativo seja efetivo, conforme a teoria histórico-cultural, a ação pedagógica deve ter em vista os estágios de desenvolvimento que ainda não foram atingidos pelo educando. Para isso, o educador deve ter ciência que seu trabalho de ensino deve incidir sobre a zona de desenvolvimento próximo do educando, a saber, sobre aquilo que o educando não é capaz de fazer sozinho, mas consegue em colaboração com um parceiro mais experiente - o educador (MELLO, 2004).

Mais ainda, para a teoria histórico-cultural, a aprendizagem só é efetiva se as ações pedagógicas desenvolvidas na escola forem realizadas enquanto atividade. O que isso significa? Significa que, para se constituir enquanto atividade, no sentido empregado por Leontiev (2004), o educando, no processo educativo, deve ter clareza do objetivo de sua ação. Para isso, a apropriação do objeto de aprendizado deve se realizar por meio de uma ação motivada. 0 educando deve responder subjetivamente a seguinte pergunta: por que realizo esta ação? Apenas nesse caso sua prática se constitui enquanto atividade, pois possuidora de sentido para ele, indivíduo. A escola e os educadores atuam de forma importante ao propiciarem a criação de motivos que concorram para a realização de atividades que tenham como fim o desenvolvimento de aptidões e capacidades humanas.

Em sua tese de livre-docência, L. M. Martins, uma das grandes especialistas nesse campo de pesquisa, associa de modo profícuo a teoria histórico-cultural à pedagogia histórico-crítica, afirmando que:

[...] o desenvolvimento do psiquismo humano identifica-se com a formação dos comportamentos complexos culturalmente instituídos, isto é, com a formação das funções psíquicas superiores, radica a afirmação do ensino sistematicamente orientado à transmissão dos conceitos científicos, não cotidianos, tal como preconizado pela pedagogia histórico-crítica (2011, p. 211)

Com base na passagem acima, é possível afirmar que, tanto para a teoria histórico-cultural quanto para a pedagogia histórico-crítica, a escola é uma instituição social importante porque se constitui enquanto um lugar socialmente destinado a realizar o ensino "sistematicamente orientado à transmissão dos conceitos científicos".

Pode-se perguntar: para a teoria histórico-cultural e para a pedagogia histórico-crítica, qual é a importância da apropriação do conhecimento científico para o desenvolvimento dos homens?

Para ambas, é somente com a apreensão dos conceitos científicos que os homens têm acesso à inteligibilidade do real, ou, em outros termos, ao real como resultado de uma síntese de múltiplas determinações. O conhecimento do senso comum aprisiona os homens no mundo da cotidianidade. Ele não nos conduz, por si mesmo, à compreensão das relações sociais complexas nas quais os indivíduos estão inseridos no todo social. A escola cumpre a função de desenvolver a individualidade para si, que somente é alcançada quando o indivíduo passa a estabelecer uma relação consciente com a sua individualidade, com a sua atividade e com o mundo, quando ele compreende os fatores sociais complexos que atuam sobre a sua subjetividade e sobre o seu ser no mundo. (DUARTE, 2013). 


\section{CONCLUSÃO}

Ao articularmos as formulações sociológicas de Berger e Luckmann com as contribuições das teorias histórico-crítica e histórico-cultural, passamos a ter uma visão mais ampla a respeito da relação entre escola e subjetividade, pois incluímos a dimensão social (institucional) à reflexão sobre o desenvolvimento da individualidade. Longe de pretender ter explorado todas as potencialidades dessa aproximação, procurei aqui tão-somente iniciar um diálogo, a meu ver, bastante oportuno e até então não explorado pela literatura especializada.

\section{REFERÊNCIAS}

BERGER, P. L.; LUCKMANN, T. A construção social da realidade: tratado de sociologia do conhecimento. Petrópolis: Vozes, 1985.

DUARTE, N. A pedagogia histórico-crítica e a formação da individualidade para si. Germinal: Marxismo e Educação em Debate, Salvador, v. 5, n. 2, p. 59-72, dez. 2013.

GERHARDT, T. E.; SILVEIRA, D. T. (Org.). Métodos de pesquisa. Porto Alegre: Editora da UFRGS, 2009.

LEONTIEV, A. N. O desenvolvimento do psiquismo. Trad. Rubens Eduardo Frias. 2. ed. São Paulo: Centauro, 2004.

MARTINS, L. M. O desenvolvimento do psiquismo e a educação escolar: contribuições à luz da psicologia histórico-cultural e da pedagogia histórico-crítica. Tese (Livre-docência em Psicologia da Educação) - Faculdade de Ciências. Universidade Estadual Paulista, Bauru, 2011.

MELLO, S. A. A escola de Vygotsky. In: CARRARA, K. (org.). Introdução à Psicologia da Educação: seis abordagens. São Paulo: Avercamp, 2004.

SAVIANI, D. Educação: do senso comum à consciência filosófica. Campinas: Autores Associados, 1996.

. Escola e democracia. Campinas: Autores Associados, 2008.

- Pedagogia histórico-crítica: primeiras aproximações. 8.ed. Campinas: Autores

Associados, 2003.

VYGOTSKY, L. Aprendizagem e desenvolvimento intelectual na idade escolar. In: VYGOTSKY, L.; LURIA, A.; LEONTIEV, A. Linguagem, desenvolvimento e aprendizagem. São Paulo: Ícone/EdUsp, 1988. 